\title{
A STUDY OF RINGED HAIR * 1
}

\section{LEE D. CADY, A.M., M.D. And MILdRED TROTTER, A.B. M.S.}

ST. LOUIS

An unusual banded appearance of the hair was described by Karsch, in 1846, under the name of Pili annulati." Such "ringed hairs" have proved to be of rare occurrence, and the few cases thus far reported have not afforded material for an entirely satisfactory account of the nature and genesis of the condition. Because of the apparent infrequency of the anomaly and some uncertainty as to its exact nature it seems desirable to report briefly on some cases that have recently been examined. These cases have all appeared in three families, one of which was being studied by the writers when the second was called to their attention by Dr. P. W. Whiting, of the University of Iowa, who generously supplied samples of hair for study. Dr. Whiting will take up elsewhere the heredity of this interesting condition. The third family has been in the practice of Dr. Martin F. Engman, Washington University, for about twenty years.

So far as we have been able to find, only eighteen cases are recorded in the literature. Since there has been no comprehensive review of this subject and no systematic microscopic study of hairs presenting this condition, it was thought desirable to review the literature up to date and to add such facts relating to the structure of ringed hairs as have been made out by a more detailed study than has previously been attempted.

\section{REVIEW OF LITERATURE}

The first case, described by Karsch in 1846 (quoted by Landois, 1866), appeared in the hair of a boy 19 years old. Some of the hairs were half dark brown and half white, others had short alternate rings of dark brown and white. Karsch concluded that the portions which appeared dark when seen under the microscope by transmitted light were the normal segments. Landois, ${ }^{1}$ however, showed that it was the light segments of the hairs that appeared dark by transmitted light, and vice versa. Karsch believed a white pigment to be present in the white segments, but according to Landois, Speiss in 1859 attributed the whiteness to the presence of air bubbles.

* From the Department of Anatomy, Washington University School of Medicine, St. Louis.

1. Landois, L.: Das ploetzliche Ergrauen der Haupthaare, Arch. f. path. Anat. u. Physiol. 35:575, 1866. 
Wilson $(1867)^{2}$ noted the condition in a boy $71 / 2$ years old. In this case it was observed to become more general during the next two years. The hair shafts were uniform and presented alternate brown $(1 / 50$ inch $[0.5 \mathrm{~mm}]$.$) and white (1 / 100$ inch $[0.25 \mathrm{~mm}]$.$) segments. He$ thought the whiteness was due to the presence of globules of air which sometimes communicated by short irregular canals. There were also air globules in the medullae.

Frazer $^{3}$ (1875) described some hair (about 13 inches [33.02 cm.] long) from an Italian woman procured from a hair dresser. Every hair had marked uniform alternate white and dark-brown bands (three brown and two white bands to an eighth of an inch [3.17 $\mathrm{mm}$.]). The hair was moderately coarse, and in both the gross and the microscopic examination presented the characteristics of otherwise normal human hair.

Crocker $^{4}$ (1893) reported the case of an 8 year old gir! whose hair had been natural and silky previous to the onset, two years before, of a condition considered to be a sequel to influenza and ophthalmia. The hair had a greater optical diameter opposite the light segments, which sometimes filled the entire diameter of the shaft, and were frequently four times as long as the pigmented segments. This infiltration commenced in the shaft just above the hair root and extended throughout the entire length of the hair. The condition was more marked on the left side of the scalp than on the right.

Unna " (1894) gave the condition the name leukotrichia annularis. His patient was a man, 26 years old, in whom part of the hairs of the scalp were affected. Those hairs in which the condition was present were dry, fragi!e and gray in appearance. The segments varied in length from mere points to 2 or $3 \mathrm{~mm}$. Microscopically the white segments seemed normal with the exception of an unusually large number of interstices. This infiltration was most marked in the medullas, but air-containing cavities extended irregularly toward the cortex. He believed that the air streaks were due to an alternate increasing and decreasing functional activity of the matrix of the hair causing alternate harder and softer segments. When the softer parts became dried, they developed air spaces within them causing the white segments in a manner similar to the production of leukonychia, as explained by Unna. Leukonychia was found associated in this case.

2. Wilson, E.: On a Remarkable Alteration of Appearance and Structure of the Human Hair, Proc. Roy. Soc. of London 15:406, 186\%.

3. Frazer: Human Hair Presenting a Remarkable Alternate Transverse Dark and White Mottling, Quart. J. of Microscop. Sc. 15:100, 1875.

4. Crocker, H. R.: Ringed Hair, Brit. J. Dermat. 5:175, 1893.

5. Unna, P. G., in J. Orth.: Lehrbuch der Specielien Pathologischen Anatomie, Erganzungsband 2, Berlin, A. Hirschwald, 1894, p. 1061. 
Frew's case (quoted by McCall Anderson, ${ }^{6}$ 1894) was that of a girl $91 / 2$ years old. The condition was of short duration and disappeared under treatment.

Kiwull $^{7}$ ( 1895 ) reported the case of a girl 20 years old with alopecia praematura universalis of three years' duration. The hair was all gone except about 50 thin hairs 1 or $2 \mathrm{~cm}$. long. Microscopically several hairs showed spindle-shaped areas which appeared dark by transmitted light and white by reflected light. He thought the white streaks were due to the presence of air.

Galloway's ${ }^{8}$ cases (1896) were those of two brothers, 8 and 10 years of age. The bands were of almost equal length, slightly less than $1 \mathrm{~mm}$. The hair had a peculiar lusterless appearance. This is the first report that indicates that the condition may be hereditary.

Brayton's ${ }^{9}$ case (1897) was noticed when the patient, a boy, was 2 years old, and the condition had persisted for fourteen years thereafter. The alternate light and brown segments gave the hair a "sandy" appearance. There were from 20 to 30 of the segments to an inch of hair shaft. The hair was becoming darker as the boy grew older. Two of the mother's brothers had similar hair, but four brothers and a sister of the boy had normal hair.

Meachen's ${ }^{10}$ case (1902) was that of a boy 8 years old. The white and the dark segments averaged 0.2 and $0.3 \mathrm{~mm}$., respectively. The infiltration of air was said to be confined to the medulla, there being always a narrow strip of normal cortical substance exterior to the abnormal segments. Melanoderma, syndactylia and polydactylism had been present from birth. Meachen was unsuccessful in establishing a bacterial origin for the condition.

Crocker's ${ }^{11}$ second case (1903) of ringed hair occurred in the mustache of a man 39 years old and was associated with trichorrhexis nodosa. Some hairs showed air bubbles in stellate heaps around the medulla at regular intervals. The dark segments were much longer than the light ones. This is the only case in which the condition is reported in hair other than that of the scalp.

Fox's ${ }^{12}$ case (1906) was associated with almost comp!ete alopecia of two months' duration in a woman 25 years of age. The few remaining hairs had a "dusty" appearance due to alternate dark $(1 / 50[0.5 \mathrm{~mm}$.]

6. Anderson, McC.: Diseases of the Skin, 1894, p. 64.

7. Kiwull, E.: Defluvium capillorum universale, Pili annulati, Arch. f. Dermat. u. Syph. 32-33:173, 1895.

8. Galloway, J.: Ringed Hair, Brit. J. Dermat. 8:437, 1896.

9. Brayton, A. W.: A Case of Ringed Hair, Ind. M. J. 16:10, 1897.

10. Meachen, F. N.: A Case of Leucotrichia annularis, Brit. J. Dermat.

$16: 86,1902$.

11. Crocker, H. R.: Diseases of the Skin, 1903, p. 1196.

12. Fox, C.: A Case of Ringed Hair, Brit. J. Dermat. 18:321, 1906. 
inch) and light $(1 / 75$ inch $[0.33 \mathrm{~mm}]$.$) segments. The woman sub-$ sequently had normal hair. Fox referred to another case of ringed hair but gave no description of it.

Haxthausen's ${ }^{13}$ case (1917) was that of a girl 18 years old in whom the condition had been present as long as she could remember. The segments were about $1 \mathrm{~mm}$. apart and were found in all the hairs of the scalp. Microscopic study, after removal of the pigment with sodium hydroxid, showed that the white segments were due to air bubbles.

Hoepke's ${ }^{14}$ case (1921) was that of a man, 23 years o!d, in whom ringed hair was said to have been present since puberty. The hair was coarse and ringed and was said to have seasonal variations in color, being light blond in summer and dark blond in winter. The rings appeared and disappeared in much the same manner as the supposed pigmentary changes. When these hairs were boiled in glycerol the light segments disappeared. Boiling in alcohol, ether, benzol and oil apparently caused no changes. The tensile strength of these hairs averaged from 80 to 90 per cent. more than average hairs. These hairs when under tension always broke between the light segments. Attempts to exhaust the gas from the light segments in vacuo were unsuccessful.

\section{MATERIAL STUDIED}

The hair specimens available to us came from two families, the $\mathrm{N}$ family and the $S$ family.

The $\mathrm{N}$ family, disregarding persons with normal hair who have married into it, consists of the maternal grandmother, $N_{1}$; her three daughters, $\mathrm{N}_{21}, \mathrm{~N}_{22}$ and $\mathrm{N}_{23}$; her two sons $\mathrm{N}_{24}$ and $\mathrm{N}_{25}$; and her three grandsons, $\mathrm{N}_{31}$ and $\mathrm{N}_{32}$, children of $\mathrm{N}_{21}$; and $\mathrm{N}_{33}$, the child of $\mathrm{N}_{23}$. Samples of hair were obtained from all members of this family except $\mathrm{N}_{1}, \mathrm{~N}_{25}$ and $\mathrm{N}_{32}$.

The $S$ family consists of the father, $S_{1}$; his son, $S_{21}$ and daughter, $\mathrm{S}_{22}$; and two grand-children, $\mathrm{S}_{31}$ and $\mathrm{S}_{32}$, twin daughters of $\mathrm{S}_{21}$. All members of this family contributed specimens of hair. Ten additional samples of hair from cousins of the $S$ family have been subsequently received from Dr. Whiting.

The $\mathrm{K}$ family consists of the grandmother, $\mathrm{K}_{1}$; three daughters, $\mathrm{K}_{21}, \mathrm{~K}_{22}$ and $\mathrm{K}_{23} ; \mathrm{K}_{31}, \mathrm{~K}_{32}$, and $\mathrm{K}_{33}$, the two sons and daughter, respectively, of $\mathrm{K}_{21} ; \mathrm{K}_{34}$ and $\mathrm{K}_{33}$, daughters of $\mathrm{K}_{22} ; \mathrm{K}_{: 3,}$ and $\mathrm{K}_{37}$, the daughter and son, respectively, of $\mathrm{K}_{23}$.

13. Haxthausen, H.: Pili Annulati, Dermat. Ztschr. 24:298, 1917.

14. Hoepke, H.: Ueber Veränderungen des Pigments und Luftgehaetes im Haar, Verhand1. der Anat. Gesellsch. 30:127, 1921. 


\section{DESCRIPTION OF MATERIALS}

The following description of "ringed hairs" refers only to those taken from the scalp. Hairs from other parts of the body were examined, but showed no evidence of this condition. Before describing the individual cases we may summarize briefly the general characteristics common to all the specimens we have examined.

To the unaided eye ringed hair shows alternating light and dark segments varying in length in different persons. The ends of the segments appear to be sharply defined. Other macroscopic points vary with the subject and will be described.

Microscopically the hair preserves a uniform diameter throughout its length, tapering toward the tips no more than in normal hairs. No variations, real or apparent, in the diameter of the hairs at the site of the bands of light and dark could be made out by careful examination and rotation of the hair shaft. By transmitted light, the macroscopically light segments appear as long irregular dark splotches, while the dark segments of the hair appear as of more or less homogeneous structure with fine pigment granules normally distributed throughout the cortex. These macroscopically dark segments may, consequently be regarded as essentially normal in structure. In order to avoid confusion in terminology those portions of the hair which appear white macroscopically and by reflected light under the microscope, but dark by transmitted light, are referred to as the aberrant segments while those parts which in all lights have the appearance of ordinary hair are called normal. Frequently the aberrant portions in the hair appear to extend almost to the cuticle of the shaft. In such cases, if the hair is rotated from 90 to 180 degrees about its long axis, this area shows variation in the configuration of what at first appeared to be its boundaries. This shows that the aberrant areas are not symmetrical with respect to all diameters of the hair shaft. The ends of the dark and light segments, though sharply defined, are not regular. The aberrant segments are surrounded by a layer of normal, pigment-bearing cortex varying in thickness as the shape and size of these segments permit. In many hairs the medulla is not to be made out with certainty and bears no definite relation to the aberrant segments, while in others it is wide and conspicuous throughout most of the length of the shaft. In these hairs the segments which are dark in transmitted light appear to be clue to widening of the dark part representing the medulla. Where the medulla thus widens to form the dark segment of the hair, no qualitative changes can be made out. In other hairs having no medulla the aberrant segments occur just as regularly and definitely and bear the same general relations to the rest of the hair shafts as in hair in which the medulla is conspicuous. When the hairs are viewed by reflected 
light the segments which were dark appear light, and the former light segments appear dark.

Although hair from $\mathrm{N}_{1}$ was not available for study, it is stated by her relatives that in early life she had the same banded type that characterizes many other members of the family, so it may be presumed that hers was a typical case of ringed hair.

The hair of $\mathrm{N}_{21}$ (Plate $1, \mathrm{~N}_{21}$ ) is of dark blond color. It is fine and soft, of normal length and thickness and, collectively, does not present the appearance of ringed hair. However, when examining the individual hairs without the aid of a glass, one can see that about onefifth of the hairs have a segmented appearance in some portion of the shafts and about one-fifth more of the hairs are doubtfully segmented. The rest of the hairs would not be classed as abnormal. Microscopically, the segmentation does not extend throughout the entire hair shaft, but hairs are found that have the condition at the tips while 2 or $3 \mathrm{~cm}$. further back the appearance is very much that of the nonsegmented hairs. That the segmentation is not confined to that part of the shaft already outside the follicle is plainly shown by a hair which had the condition in the basal $3 \mathrm{~mm}$. of its shaft. The root of this hair showed segmentation with the same interval of spacing that the portion above the skin showed. The whiteness appears in the shaft some time after it is well cornified, but still within the hair follicle. Those hairs that to the unaided eye have a doubtfully segmented appearance show slight microscopic indications of segmentation. The so-called air infiltration appears dark by transmitted light and occurs for the most part only in traces, but at more or less regular intervals.

The hair of $\mathrm{N}_{22}$, aged 49 , is mostly gray. Some of the hairs appear more white than others and occasionally one finds a short segment whiter in appearance than the rest of the hair. The few pigmented hairs are medium brown. No macroscopic segmentation is present. The white segments in the gray hairs and the hairs that look especially white have conspicuous medullas. There is no segmentation in the cortex.

The hair of $\mathrm{N}_{23}$, aged 33, is reddish-brown, or auburn, and is normal.

$\mathrm{N}_{24}$, aged 36 , has dark hair with an occasional gray hair. Approximately one-half of the hairs show macroscopic segmentation. About one-half of the remaining hairs show microscopic segmentation (Fig. 1, $\mathrm{N}_{24}$ ).

The hair of $\mathrm{N}_{31}$, aged 25 , is of normal growth and presents a rather peculiar light leaden appearance which on closer inspection resolves itself into alternate bands of gray and dark blond. All of the hairs have the segmentation, but occasionally one is found that is not uniformly segmented. Microscopically the hairs are quite typical of ringed hair (Plate $1, \mathrm{~N}_{31}$, upper hair). Examination of these hairs within one-half hour after pulling them out of their follicles does not 
show any difference in the position of the dark segments with reference to the hair bulb from that observed when the same hairs are eximined several days later.

No specimen is available from $N_{32 .}$. lut his hair is said to be of normal growth but similar in appearance to that of $\mathrm{N}_{31}$.

We were unable to secure a satisfactory number of hair specimens from $N_{: 3,}$, aged 19 , for study. In the specimens available no macroscopic evidence of segmentation is visible until the hairs are mounted in balsam when segments of irregular length appear lighter in color.

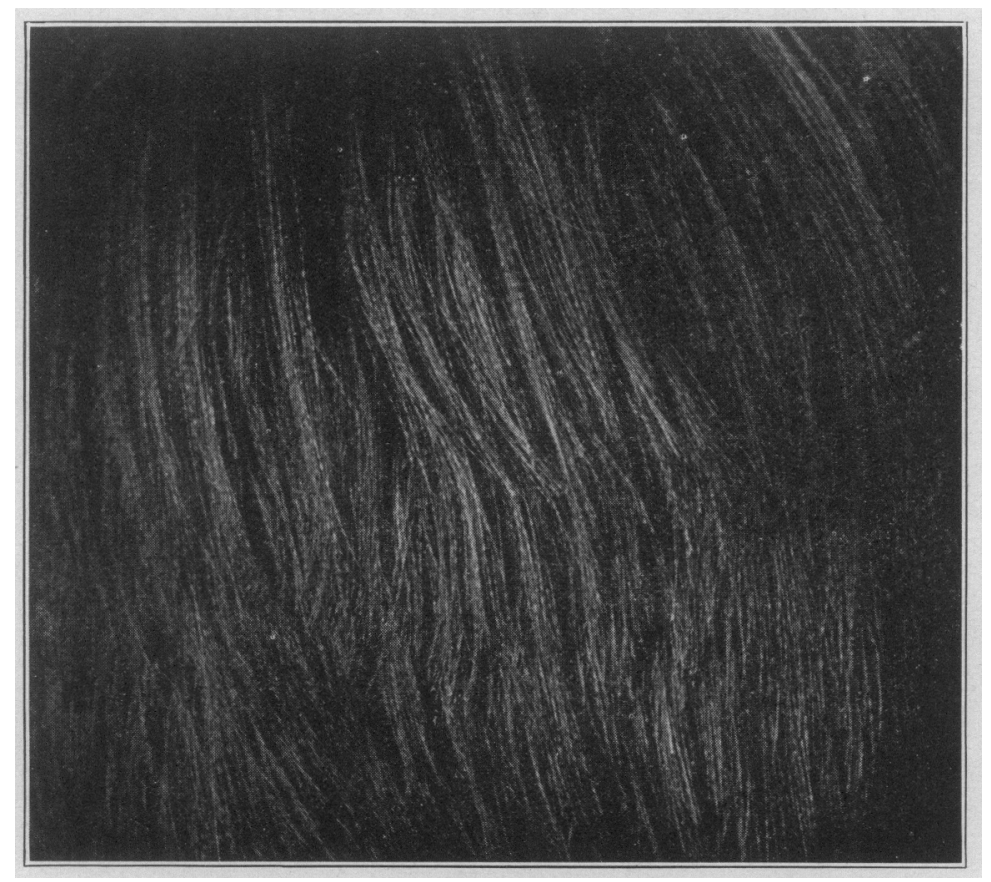

Fig. 1.-Photograph of back of head of $\mathrm{N}_{\mathrm{*} \text {. }}$.

These lighter segments (by reflected light) correspond in position to segments of the medullas which are dark by transmitted light. There is no eviclence of segmentation of the cortex.

In the $S$ family, the hairs from the head of $S_{1}$, aged 58 , are iron gray and brown. All of the gray hairs show segmentation into alternate opaque and rather translucent portions of the hair shafts, while approximately only one-half of the pigmented hairs are segmented. The segmentation is much more conspicuous in the gray hairs than in the pigmented hairs. As a whole, the segments are of uniform dimensions, but occasionally a hair is found that is not uniformly segmented. Microscopically the gray hairs are remarkably transparent (Fig. 1. S ) $_{1}$. 
There are slight indications of pigmentation in the cortical substance of these hairs. One can get a glimpse of light penetrating through the optically dark segments that cannot be seen in the pigmented specimens of ringed hair. Under a higher magnification the supposedly normal segments are seen to be rather diffusely sprinkled with small dark areas.

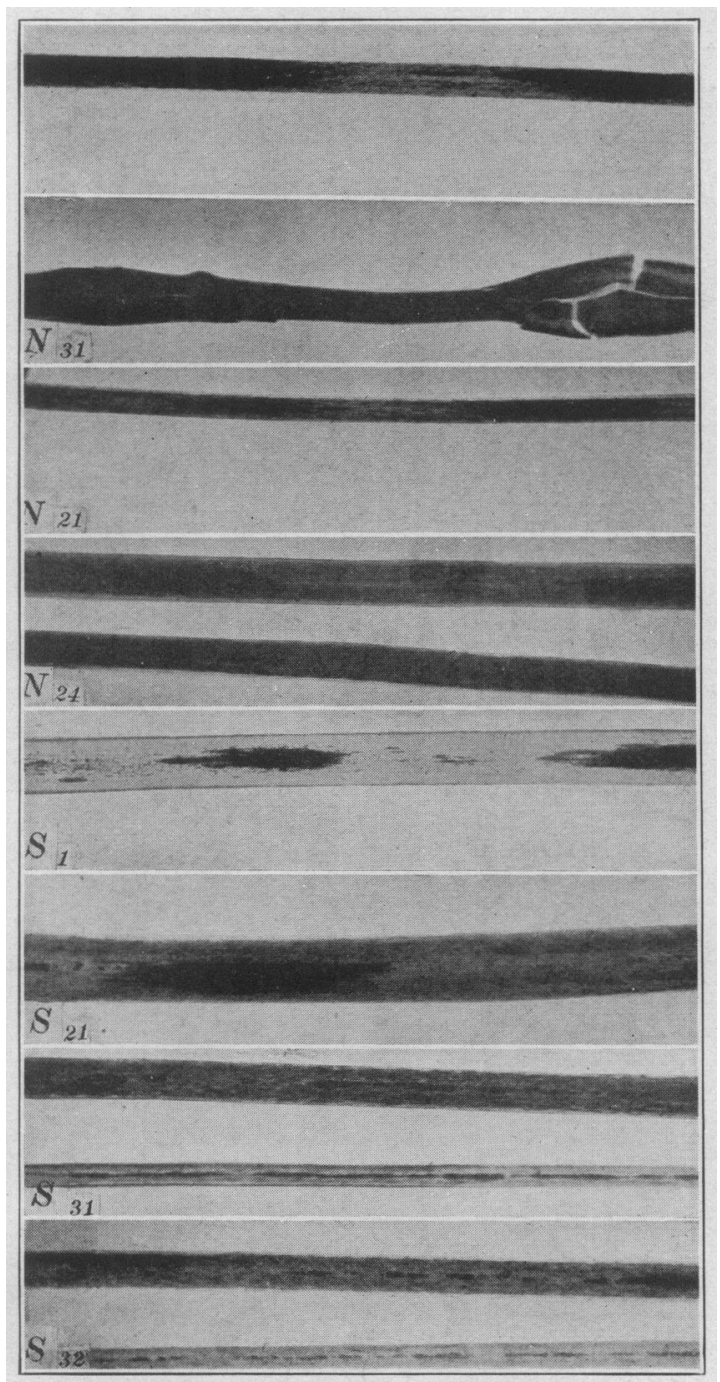

Fig. 2.- $\mathrm{N}_{31}$, the upper part $(\times 40)$ illustrates a typical hair of $\mathrm{N}_{31}$; the lower part $(\times 40)$ a hair of $N_{31}$ boiled in liquid petrolatum. $N_{21}$, photograph ( $\times 40$ ) of typical ringed hair of $N_{21}$. $N_{24}$, upper part illustrates ringed hair, lower, normal hair from $N_{24}(\times 73)$. S $S_{1}$, typical ringed gray hair of $S_{1}(\times 73)$. $S_{21}$, typical ringed hair of $S_{21}(X 73)$. $S_{31}$, ringed hair and normal hair with large medulla from $S_{31}(\times 73)$. $S_{32}$, ringed hair and normal hair with large medulla from $S_{32}(\times 73)$. 
Where the ends of the hairs have been cut, there is no predominance of one type of segment cut through over the other. By reflected light the macroscopically white sections show up as clean-cut silvery areas. The same may be said of the small dark points between the white segments.

The hair of $\mathrm{S}_{21}$, aged 30 , is rich brown in color with an occasional gray hair, and it is only by careful examination of the individual hairs over a dark background that segmentation becomes apparent in about one-third of the hairs. Some of the hairs show the segmentation at the tip and others show it near the base, while still others show it throughout the entire length (Fig. 1, $S_{21}$ ). Microscopically many of the aberrant segments seem to be expansions of the medulla and show only inconspicuous medullary connections with each other. Smaller infiltration areas are no doubt an important factor in making the segmentation macroscopically less conspicuous in $\mathrm{S}_{21}$ than in $\mathrm{N}_{31}$ where the condition is typical. Many of the hairs that show marked segmentation also show large conspicuous medullas which extend almost uninterruptedly throughout the entire hair shafts.

The hair of $S_{22}$, aged 21, is of medium dark color. None of the hairs shows macroscopic or microscopic segmentation.

$S_{31}$ and $S_{32}$, aged 13 months, have fine silky light brown hair with no macroscopic indications of any abnormalities. Microscopically the medulla is quite conspicuous, extending throughout the entire hair shaft as a relatively wide dark streak (by transmitted light). There are many interruptions of the continuity of the air-containing portions of the medulla which occasionally has a regularity that suggests segmentation. Portions of a hair that show unmistakable traces of cortical segmentation can be found (Fig. 1, $S_{31}$ and $S_{32}$ ).

As this paper was being finished Dr. Whiting kindly sent us samples of hair from ten relatives of the $\mathrm{S}$ family. Of these, five showed unmistakably the ringed form. Two of the latter were for the most part gray and resembled the hairs from $S_{1}$. The other three presented nothing calling for special mention except that in at least one of thent the banding became much less conspicuous after thirty minutes in thin balsam. This suggests the desirability of always examining hairs fresh or immediately after mounting.

$\mathrm{K}_{1}$, at the age of 70 , applied to Dr. Engman, about twenty years ago, for treatment for a gradually increasing bald spot in the center of the occiput. The patient's hair had never been abundant in growth and was at that time very coarse, sparse and gray. The ringed condition was conspicuous.

$\mathrm{K}_{21}, \mathrm{~K}_{22}$ and $\mathrm{K}_{23}$, daughters of $\mathrm{K}_{1}$, all have unmistakable ringed hair.

$\mathrm{K}_{31}$, a man of 21 when seen by Dr. Engman, was almost entirely bald. Such hair as did grow was very fine and fragile and showed the 
ringed condition. Eventually he became entirely bald. The eyebrows were patchy.

$\mathrm{K}_{32}$ had a rather heavy growth of ringed hair and like his older brother was becoming bald on the occiput. His sister, $K_{33}$, had exceedingly tenuous, rich brown hair of normal growth. It was markedly ringed.

$\mathrm{K}_{34}$ and $\mathrm{K}_{3 \bar{n}}$, daughters of $\mathrm{K}_{22}$, had fine, rich brown hair. The ringed condition was present in both. There was no tendency toward falling out or breaking off of the hair.

$\mathrm{K}_{36}$, the daughter of $\mathrm{K}_{23}$, had hair of more than average length and normal in every respect except that it was ringed. Her brother, $\mathrm{K}_{37}$, is now 30 years old, has ringed hair, but shows no other abnormal tendencies.

\section{EXPERIMENTAL DATA}

The problem of determining the physical and chemical factors which cause the unusual appearance of these hairs presents itself, but it is outside the scope of this investigation to determine whether or not the condition can be produced experimentally. The following laboratory tests were made on representative speciments of ringed hairs in order to better establish or to disprove previous ideas about the presence of air in the hair substance as the cause for the white appearance of what otherwise seemed to be normal hair of a different color.

It is commonly recognized that the medulla of a hair often appears as a dark streak by transmitted light, due to the refraction of light by the walls of its air-containing spaces (MacLeod, ${ }^{15}$ 1903). When normal hairs are soaked in oil and then viewed by transmitted light, the medullas no longer show up as dark streaks because of the light transmitting power of the oil which finds its way into the air spaces. When ringed hairs are put into liquid petrolatum and kept at about $70 \mathrm{C}$. for six or seven days, the aberrant segments are represented only by the outlines and traces of their former configuration. When the hairs were boiled in liquid petrolatum or kerosene for from ten to fifteen minutes, they became bright reddish brown, probably due to the yellowing effect of the oil within them and to a slight charring of the hair. Some of the hairs ruptured and appeared lighter in color than others. In these all traces of the white segmentation were gone. The hairs that retained their continuity still showed traces of their former banded appearance which was manifested by slight nodosity where the white segments had previously been located. Under the microscope the ruptured hairs showed large bubbles throughout their cortices and the medullas had enlarged so that the hairs had irregular central canals which connected

15. MacLeod, H. M. H.: Handbook of the Pathology of the Skin, London, Lewis, 1903, p. 213. 
with almost every line of fracture in the cortex. Where the normal segments had previously been located only a smaller collection of bubbles remained. When pressure was exerted on the coverslip the hair was easily crushed leaving many fragments of hair and a line of bubbles, the largest of which were in positions corresponding to the former aberrant segment and subsequent nodosities mentioned in the foregoing.

Those hairs that had retained their integrity no longer showed the segments after they had been boiled enough to cause the appearance of the bubbles within them. Instead of the white segments there appeared to be relatively large cavities which were usually of sufficient size to cause the outlines of the hair to bulge opposite them, thus giving a beaded appearance suggestive of monilothrix (Fig. 1, $\mathrm{N}_{31}$ ). Sometimes these cavities had ruptured and were filled with clear oil which permitted their walls to show up as normally pigmented hair cortex. Those portions of the medulla which after slight treatment appeared to be

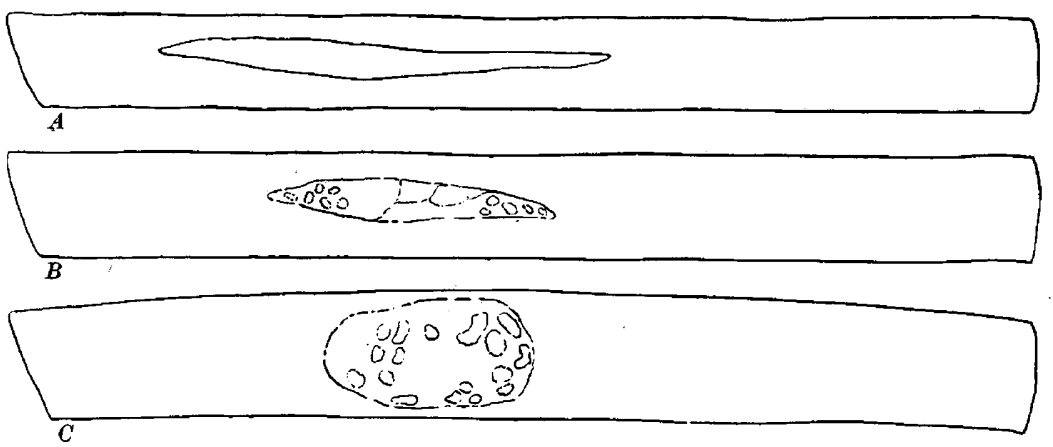

Fig. 3.- $A$, a camera lucida sketch including the outline of an aberrant segment (dark by transmitted light). $B$, the same segment after boiling in kerosene for five minutes; $C$, the same segment after boiling in kerosene for ten minutes $(\times 135)$.

patent and the small dark spots in the normal segments had likewise become frank cavities. These cavities had the appearance of globular gas bubbles. Unfortunately they could not be made to show in photographs, but the sketches (Fig. 3) are camera lucida outline drawings of the changes that take place while boiling in kerosene. The particular aberrant segment selected was not associated with a continuous medulla. Fig. $3 A$ shows the outline of the aberrant portion before boiling in oil. Figures $3 B$ and $3 C$ show the same hair segment after several minutes in boiling oil.

When hairs were subjected to the oxidizing action of nascent chlorin for forty-eight hours, they lost all their pigment and took on the appearance of normal, gray hair, but microscopically they presented an appearance suggestive of that in the untreated gray hairs of $S_{1}$. 
The cortex was the same throughout. The medulla was clearly discernible with regular enlargements and constrictions corresponding in position to the light and dark segments, and extending throughout the length of the hair shafts. This observation furnishes an additional proof that the banding of the hair is not dependent on variations in pigment.

There are some indications that the gas globules in the hair are composed of carbon dioxid. If one of these hairs is immersed in a 5 per cent. solution of sodium hydroxid which has been thoroughly saturated with all the elements of air which obey the physical laws of partial pressures for gases in such a solution, the segmented appearance nevertheless disappears. This would not be expected if the gas were ordinary air, for the solution of sodium hydroxid would only be capab'e of chemically absorbing the very small percentage of carbon dioxid found in the air, and not the nitrogen, oxygen, etc. Since all the gas is absorbed by the sodium hydroxid, it is fair to assume that it may be carbon dioxid. Hairs treated in this manner swell and become softened but when thoroughly washed and dried they return to their normal size and recover their usual stiffness, seeming to be no more brittle than before treatment. But the segmented appearance does not return. Normal hairs with large medullae were treated with sodium hydroxid, but in these the medullae did not disappear so long as the hairs remained intact.

One of the segments was photographed at various stages of its disappearance in a 5 per cent. solution of sodium hydroxid at room temperature (Fig. 4). From the photographs it can be seen that the hair swelled to almost twice its normal size. During the course of such treatment the white segment is soon replaced by several globules which gradually grow in size until they occupy the space of practically the whole segment. In Fig. $4 \mathrm{~B}$, taken nine and one-half minutes after the chemical treatment was begun, the bubbles have already begun to decrease in size. Finally they disappear entirely (Fig. $4 \mathrm{D}$ ). One would expect just this sort of reaction to occur if the white segments were caused by the aggregation of many very small interstices filled with carbon dioxid. Apparently as the hair substance becomes softened and swells by the action of the sodium hydroxid, the interstices enlarge and many of their very delicate walls break down letting the gas in them coalesce, thereby gradually forming appreciable globules. As the reaction proceeds there comes a time when the sodium hydroxid reaches what we assume to be carbon dioxid and absorbs it. This causes the gradual disappearance of the globules. It is possible to observe the formation and disappearance of the globules only under the high power lens, for under a low power lens the bubbles are not apparent and the dark segments merely appear gradually to fade away leaving the hair shaft homogeneous in appearance throughout. 
Considerable difficulty was encountered when attempts were made to make erial transwerse sections of these hairs. After many trials some succes was attained by first putting a coating of thin pyroxylin over the hair and quiclily following this by another coat of thick pyroxylin. This was hardenerl in chloroform for about twenty minutes and then

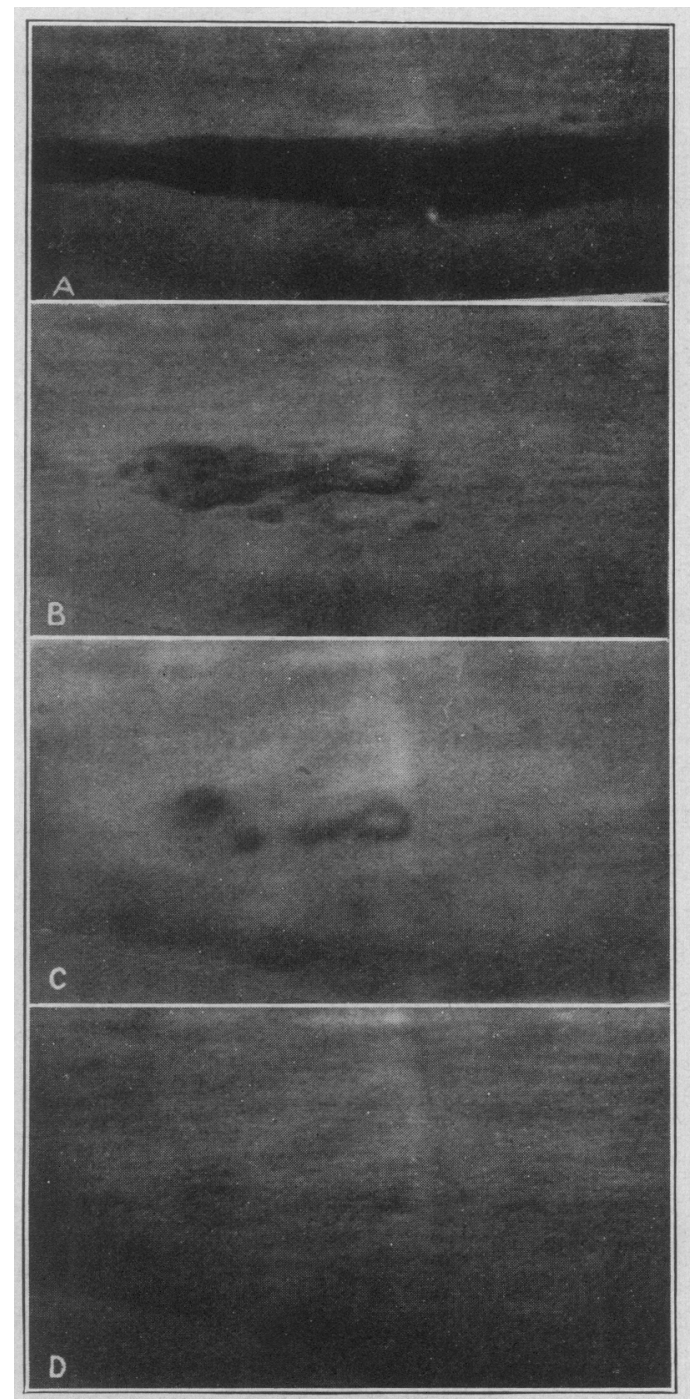

Fig: 4.- f, representative white segment (by transmitted light) of a hair irmin $X_{31}(\times 355)$ : $B$. same segment after nine and one-hali minutes treatment with 5 per cent. sodium lyclroxid $(X 355):(C$, same segment after fourteen minutes treatment with 5 per cent. sodium hydroxid $(X 355)$; $D$. same segment after eighteen minutes treatment with 5 per cent. solium hydroxid $(\times 355)$. 
imbedded in hard paraffin and sectioned with a rotary microtome. By this method satisfactory sections from 15 to 20 microns thick were obtained. It was found convenient to dip the pyroxylin coated hair in an eosin solution before imbedding. This made the sections more conspicuous and saved a great deal of time in locating them on the slide. The paraffin ribbons were mounted on albumin coated slides and as soon as they were dry the paraffin was carefully dissolved off. To prevent the loss of sections it was necessary to exercise extreme care to maintain the slide almost level and to drop the xylol on the slide carefully. By following this technic, it was found to be unnecessary to let the ribbons dry on the slide. As soon as the xylol had evaporated off the slide, locations of the sections were marked by drawing rings around them with ink. A cover-glass was then put on in balsam.

A study of sections prepared in this manner showed that the dark areas were somewhat smaller than they had appeared to be in the intact

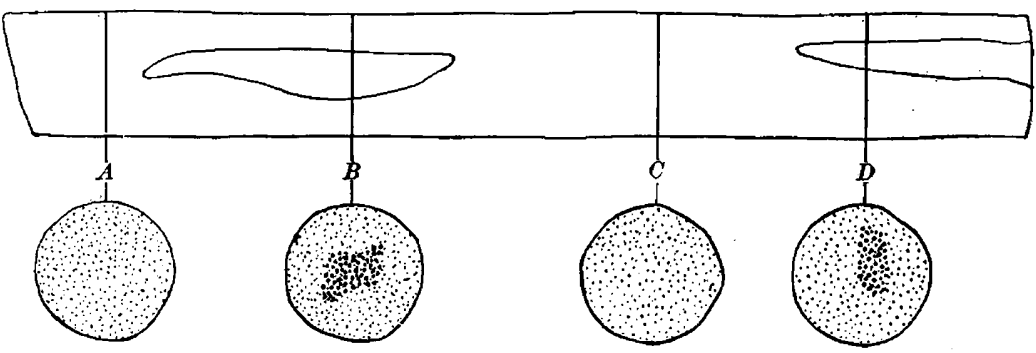

Fig. 5.-Camera lucida sketch of ringed hair and transverse sections of the same at the levels indicated by $A, B, C$ and $D(\times 135)$.

hair, a fact no doubt to be attributed to the magnification concomitant to their centrally placed position in the shaft. The upper portion of Figure 5 is a camera lucida sketch of a hair before sectioning, and the lower portion is made up of sketches of the transverse sections at the places indicated by the lines across in the upper part of the sketch. It will be seen that where the aberrant segments are sectioned there is also a darker portion (by transmitted light) in the transverse sections. Where the sections were cut thinner than 15 microns, it was difficult to make out this area with definiteness. The sections between the aberrant segments show a more or less homogeneous hair cortex, and in the hair figured no medulla. These sections failed to reveal any apparent open spaces among the cells, but as well as could be made out these dark areas were made up of the keratin walls of very small interstices which reflected some of the transmitted light out of the field. Examination of the sections under the high power lens has added nothing to what could be seen under the low power. 
DISCUSSION

If one is to judge the frequency with which ringed hair is to be observed in the white race by the number of references in the literature, it is a rare condition. From the summary it may be seen that only eighteen cases have been mentioned and that of these only fourteen have been described. Six of these cases were in females. There is no reference in the literature to any cases in which the condition has been transmitted directly from one generation to the next, but there is one case in which it occurred in a brother of the subject and another case in which it occurred in two maternal uncles. There is no effective attempt to assign to it a reasonable etiologic factor except heredity.

Review of Cases in the Literature

\begin{tabular}{|c|c|c|c|c|c|c|}
\hline Author & Date & Sex & $\begin{array}{l}\text { Age, } \\
\text { Years }\end{array}$ & $\begin{array}{l}\text { Dura- } \\
\text { tion, } \\
\text { Years }\end{array}$ & $\begin{array}{l}\text { Family } \\
\text { History }\end{array}$ & $\begin{array}{l}\text { Associated Condition } \\
\text { and Remarks }\end{array}$ \\
\hline 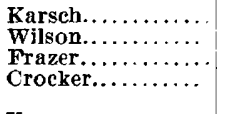 & $\begin{array}{l}1846 \\
1867 \\
1875 \\
1893\end{array}$ & $\begin{array}{l}\mathbf{M} \\
\mathbf{M} \\
\mathbf{F}(?)\end{array}$ & $\begin{array}{l}19 \\
71 / 2 \\
? \\
8\end{array}$ & $\begin{array}{l}? \\
2 \\
? \\
2\end{array}$ & $\begin{array}{c}\text { None } \\
\text { None } \\
? \\
\text { None }\end{array}$ & $\begin{array}{l}\text { None } \\
\text { None } \\
\text { ? } \\
\text { Noticed following influenza and } \\
\text { contagious ophthalmia }\end{array}$ \\
\hline 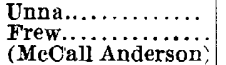 & $\begin{array}{l}1894 \\
1894\end{array}$ & $\mathbf{M}$ & $\stackrel{26}{91 / 2}$ & $\begin{array}{l}? \\
1\end{array}$ & $\stackrel{?}{\text { None }}$ & $\begin{array}{l}\text { Loukonychia } \\
\text { Condition disappeared }\end{array}$ \\
\hline Kiwull............ & 1895 & $\mathbf{F}$ & 20 & 3 & None & $\begin{array}{l}\text { Alopecia prematura universalís } \\
\text { (neurotica?) }\end{array}$ \\
\hline Galloway. . & 1896 & $\left\{\begin{array}{l}\mathbf{M} \\
\mathbf{M}\end{array}\right.$ & $\begin{array}{r}8 \\
10\end{array}$ & $\begin{array}{r}8\} \\
10\}\end{array}$ & Brothers & $\begin{array}{l}\text { Hair had pecullar lusterless ap- } \\
\text { pearance }\end{array}$ \\
\hline $\begin{array}{l}\text { Brayton........... } \\
\text { Meachen......... }\end{array}$ & $\begin{array}{l}1897 \\
1902\end{array}$ & $\mathbf{M}$ & $\begin{array}{r}16 \\
8\end{array}$ & $\begin{array}{r}14 \\
8\end{array}$ & $\begin{array}{l}2 \text { uncles } \\
\text { None }\end{array}$ & $\begin{array}{l}\text { "Sandy" appearance } \\
\text { Syndactylia, polydactylism and } \\
\text { melanoderma }\end{array}$ \\
\hline $\begin{array}{l}\text { Crocker............ } \\
\text { Fox............. }\end{array}$ & $\begin{array}{l}1903 \\
1906\end{array}$ & $\begin{array}{l}\mathbf{M} \\
\mathbf{M}\end{array}$ & $\begin{array}{r}39 \\
25 \\
?\end{array}$ & $?$ & $\begin{array}{l}\text { None } \\
\text { None } \\
\text { ? }\end{array}$ & $\begin{array}{l}\text { Trichorrhexis nodosa } \\
\text { "Dusty" appearance } \\
\text { Student }\end{array}$ \\
\hline $\begin{array}{l}\text { Haxthausen.................... } \\
\text { Hoepke.... }\end{array}$ & $\begin{array}{l}1917 \\
1921\end{array}$ & $\underset{\mathbf{M}}{\mathbf{M}}$ & $\begin{array}{l}18 \\
23\end{array}$ & $\begin{array}{l}18 \\
10(?) !\end{array}$ & $\begin{array}{l}\text { None } \\
? ?\end{array}$ & $\begin{array}{l}\text { Present in all the hairs of the head } \\
\text { Hair said to show seasonal varia- } \\
\text { tions }\end{array}$ \\
\hline
\end{tabular}

We do not believe that any of the associated conditions mentioned by previous writers can be proved to have been responsible for the hair condition described in these persons.

The condition occurs in various degrees and no doubt there have been many unreported instances of it in the families of the patients previously described. Two of the families in which we have found it to occur do not seem to attach any particular importance to it nor to be very much interested in it even though they are above the average in intelligence. For instance, $\mathrm{N}_{31}$ knew that his maternal grandmother and his mother had the condition in their early life and that it is present in his only brother, but he did not know that it is still present macroscopically in his mother and present to a greater extent in his maternal uncle. Our three families have members in whom only normal hair is found. It occurs in females in more than the reported ratio as gathered from the literature. It obviously may be an inherited condition, and 
not an acquired condition, for none of the members of these two families have undergone experiences that could be held responsible for it. The mere fact that it has been found in persons who have harl other abnormal conditions does not indicate that any one of the diseases named in the literature as associated with it can be an etiologic factor. Indeed, their diversity is entirely too great, and conversely, thousands of people have had the same diseases without having ringed hair. The cases of Galloway and Brayton, respectively, show that the condition occurs in families, and our three families show that it may be directly transmitted from one generation to another.

As to the cause of the whiteness in the white segments, we can simply state that it is caused by the presence of very minute spaces filled with gas. The walls of these spaces reflect the light incident to them thereby causing segments of the hair to appear white by reflected light as seen under ordinary conditions. For this reason the white segments of the hairs are not true gray in the accepted sense. In a hair of $S_{1}$ et al. there are both truly gray hair and hair that appears white on account of the presence of gas cavities within them. The segmented condition is more conspicuous in hairs gray by senescence than it is in pigmented hair. In the latter we have shown that the same kind and amount of pigment exists in the white segments as in the dark segments, and there is no question of a pigmentary atrophic condition as suggested by Meachen.

Kaposi ${ }^{16}$ (1895) does not think that the presence of air bubbles in the hair can cause graying of hair. Strong ${ }^{17}$ (1921) states that hair is white for the same reason that any transparent substance in a finely divided state is white. He looks on hair as being made of numerous cornified epithelial cells more or less completely fused. These cells furnish many reflecting surfaces and the amount of undispersed light reflected depends on the number of the internal reflecting surfaces not screened by pigment. We agree with this view, but it seems that in addition to this kind of whiteness another slightly different kind occurs as in the condition under discussion in which the reflecting surfaces are relatively farther apart than in the normal hair, thereby allowing less screening by pigment. We feel that there can no longer be any doubt that hair may appear white as a result of the presence of gas spaces in its substance.

\section{CONCLUSIONS}

The appearance of pili annulati is caused by gas-filled interstices in the cortex and medulla of the hair.

16. Kaposi, M.: Pathology and Treatment of Diseases of the Skin, English Trans.. 1895, p. 486.

17. Strong. R. M.: The Causes of Whiteness of Hair and Feathers, Science 54:356, 1921. 
The condition occurs in normally pigmented hair and in hair turned gray as a process of senescence. It is not due to a lack of pigment or to pigment atrophy.

There is no evidence that the condition is caused by any known pathologic process.

It may vary in the degree to which it affects an individual hair, and may vary widely in the number of hairs it affects in different persons.

The condition is compatible with the normal growth of hair.

It may be transmitted by heredity directly from one generation to the next. 